удК 341.176

\author{
М.В. Шугуров
}

\title{
НАУЧНО-ТЕХНОЛОГИЧЕСКАЯ ИНТЕГРАЦИЯ ЕАЭС КАК ФАКТОР ДОСТИЖЕНИЯ ЦЕЛЕЙ УСТОЙЧИВОГО РАЗВИТИЯ: АНАЛИЗ ПРАВОВЫХ ОСНОВ
}

\author{
Работа выполнена при финансовой поддержке РФФИ (проект № 17-03-00400-ОГН «Международно-правовое \\ регулирование передачи технологий в контексте глобальной стратегии устойчивого развития: состояние и перспективы»).
}

\begin{abstract}
Исследуются правовые основы интеграции ЕАЭС в сфере науки, технологий и инноваций в контексте региональной политики перехода к устойчивому развитию и достижению его целей в качестве нового аспекта феномена евразийской интеграции. Сделан вывод о функционировании ключевых секторальных направлений правовой политики ЕАЭС в сфере развития и передачи «зеленых технологий». Результатом проведенного исследования является концептуальное положение о том, что технологическая модернизация ЕАЭС в эколого-центричном формате предполагает углубление экономической интеграции на региональном уровне, формирование скоординированной экологической политики и развитие регионального экологического законодательства.

Ключевые слова: Евразийский экономический союз; технологическая модернизация; устойчивое развитие; защита окружающей среды; зеленые технологии; региональная интеграция.
\end{abstract}

К одному из заметных явлений современного международного инновационного и научно-технологического сотрудничества (далее - МИНТС) государств относится региональная интеграция в сфере генерирования научных знаний и технологий, их распространения и внедрения на уровне международных организаций региональной экономической интеграции при одновременном взаимодействии с третьими государствами и иными международными организациями. Со всей определенностью можно сказать, что сегодня интеграция в научно-технологической сфере является составной частью региональных интеграционных проектов. Как показывает опыт ЕC, данная интеграция осуществляется в форме развития общего научнотехнологического и инновационного пространства, функционирующего в рамках региональной инновационной системы. Сущность взаимодействия государств, а в конечном счете многообразных участников научно-технологического и инновационного процесса заключается в переходе от конкуренции к сотрудничеству, что вполне соответствует логике вертикальной интеграции в экономической сфере.

Рассматриваемая интеграция, являющаяся результатом осуществления согласованной научнотехнологической (в случаях достижения наивысшей степени интеграции - единой) политики государств, будучи основана на праве региональных союзов, преследует собой такие цели, как повышение глобальной конкурентоспособности и переход к новому технологическому укладу. При этом не следует забывать и о более масштабных целях, которые стали составной частью стратегии региональных интеграционных объединений государств. Мы имеем в виду Цели устойчивого развития (далее - ЦУР), сформулированные в Повестке дня в области устойчивого развития на период до 2030 г. (далее - Повестка2030) [1].

В развитие данной Повестки на уровне ЕС, например, разработана региональная стратегия перехода к устойчивому развитию [2], которая, несомненно, оказывает воздействие на содержание научно- технической политики в направлении разработки и внедрения технологий, обеспечивающих формирование и рост «зеленой» экономики. Данная логика эволюции повестки научно-технологической и инновационной интеграции характера и для Евразийского экономического союза (далее - ЕАЭС).

Следует отметить, что несмотря на достаточно короткий срок своего функционирования ЕАЭС добился определенных успехов в научно-технологической и инновационной интеграции. Однако, несмотря на существование целого ряд исследований, в которых анализируются достижения и проблемы научнотехнологического развития ЕАЭС сквозь призму реализации интеграционного проекта [3-5], заметно отсутствие исследования данных процессов в контексте реализации стратегии устойчивого развития, нацеленной, как известно, на гармонизацию трех измерений развития - экономического, социального и экологического. Поэтому, безусловно, оформилась актуальная потребность в концептуальном осмыслении правовых и политических аспектов динамичным образом конкретизирующейся научно-технологической интеграции ЕАЭС в свете достижения Целей устойчивого развития и формирования региональной стратегии устойчивого развития.

В качестве исходного тезиса выскажем положение о том, что интеграционный проект ЕАЭС в настоящее время начинает насыщаться вопросами реализации стратегии устойчивого развития, что самым непосредственным образом воздействует на повестку региональной интеграции в научно-технологической и инновационной сфере. В целях обоснования высказанного тезиса напомним, что Повестка-2030, предполагающая комплексный подход к развитию, вслед за предшествующими документами программно-стратегического характера, например Повестки дня на XXI в. (принятой в 1992 г.), в качестве одного из инструментов выполнения политических обязательств по гармонизации и согласованию трех измерений развития выделяет разработку и передачу научнотехнических средств в целях их использования. Сюда 
относятся не только научно-обоснованные методы и подходы, альтернативы, ноу-хау, но и инновационные технологии, получившие название «зеленых», находящиеся в основе рациональных моделей потребления и производства и предназначенные для достижения ЦУР. Более того, ЦУР № 17 помимо таких средств перехода к устойчивому развитию, как финансирование, инвестиции и формирование потенциала, выделяет разработку и передачу, особенно развивающимся странам, экологически обоснованных технологий (задача 17.6). Несмотря на то, что Повестка-2015 является документом политического характера, она играет значительную роль в стимулировании наиболее эффективной имплементации международно-правовых обязательств в сфере МИНТС, затрагивающих вопросы разработки и передачи технологий.

Реализация стратегии устойчивого развития в том виде, как она выражена в целевых задачах Повестки2030, предполагает не только активизацию национальной политики в сфере науки, технологий и инноваций, но и развитие международного научнотехнического и инновационного сотрудничества на универсальном и, конечно же, региональном уровне в направлении ускорения разработки и использования технологий в составе иных научно-технических средств, релевантных ЦУР. Тем не менее заинтересованность ЕАЭС в вопросах устойчивого развития подчас ускользает из поля внимания исследователей [6; 7. Р. 18-23]. Это зачастую приводит к узкому представлению о целях функционирования Союза, когда, например, его основная задача усматривается в координации макроэкономических стратегий [8. Р. 64]. Тем не менее с методологической точки зрения более правильно принимать во внимание подход, согласно которому идея евразийской интеграции представляет собой динамическое явление [9. Р. 104]. Как нам представляется, одним из источников такого динамизма является реализация политических обязательств по переходу к устойчивому развитию на региональном уровне.

Во многом это связано с тем, что процессы глобализации современного мира сопровождаются таким явлением, как регионализация, выражающаяся в динамичных процессах интеграции в экономической, социальной и природоохранной сферах на уровне разнообразных объединений и альянсов государств, но особенно на уровне международных организаций региональной экономической интеграции, которая теснейшим образом пересекается с научнотехнологической интеграцией. К тому же в п. 73 и п. 74 Повестки-2030 отмечается важное значение регионального уровня перехода к устойчивому развитию. Поэтому Цели устойчивого развития задают новое направление интеграционных процессов в самых различных сферах, в том числе в сфере научного и научно-технологического сотрудничества.

Развивая данный подход, укажем, что государства ЕАЭС, во-первых, предпринимают шаги на национальном уровне по достижению ЦУР, включая их в планы и стратегии национального развития. Учет данных факторов можно усмотреть в том, что, например, на 2017 г. Казахстан включил 61\% целевых задач
Повестки-2030 в свои программно-стратегические документы. Во-вторых, следует отметить разного рода инициативы, предпринимаемые не только на внутригосударственном, но и межгосударственном уровне, например, - по реализации разного рода экологических проектов, осуществляемых на уровне двухстороннего сотрудничества и многостороннего сотрудничества ЕАЭС и его государств-членов с международными организациями [10].

Но самое основное - то, что Евразийская экономическая комиссия (далее - ЕЭК) в 2017 г. при опоре на статистические материалы, отражающие динамику решения ряда задач ЦУР в государствах-членах, подготовила доклад «Показатели достижения Целей в области устойчивого развития в регионе ЕАЭС» [11], который был представлен в рамках Политического форума высокого уровня по устойчивому развитию. Надо отметить, что ЕАЭС из всех интеграционных объединений первым представил доклад о прогрессе достижения ЦУР на региональном уровне. В контексте предмета нашей статьи согласимся с общим выводом Доклада о том, что достижение ряда целей в области устойчивого развития, например ЦУР № 9 (инновационная модернизация экономики), требует наращивания усилий в рамках Союза по разработке и использованию ресурсосберегающих технологий и высокотехнологичных производств.

Ввиду тесной связи между интеграционной повесткой и содержательной направленностью регионального МИНТС перспективным направлением работы может выступить формирование повестки устойчивого развития ЕАЭС как таковой, например, в виде стратегии как основы проведения соответствующей скоординированной политики. Так, в литературе отмечается, что государства ЕАЭС не только должны уточнить свои национальные программностратегические документы в свете принятия ЦУР, но и выработать Цели устойчивого развития ЕАЭС [12. С. 6]. Думается, что здесь имеется значительный потенциал политической воли, поскольку, как это следует из программы российского председательства в ЕАЭС в 2018 г. [13], предполагается не только сфокусироваться на реализации цифровой повестки, но и сконцентрироваться на содействии имплементации Целей устойчивого развития и участии в других инициативах ООН. При этом надо помнить, что ключевая тенденция глобального технологического развития это не только переход к новым технологическим укладам, но и его форматирование в целях обеспечения устойчивого экономического роста и согласования трех измерений развития. Данная тенденция находит свою конкретизацию на региональном и национальном уровнях, в том числе в ЕАЭС и его государствах-членах.

Разработка и принятие Повестки-2030 происходили в одно и то же время с разработкой, подписанием и вступлением в силу важнейших актов, образующих право ЕАЭС. Однако мы не можем сказать, что их содержание исключительным образом имело в виду глобальные Цели устойчивого развития, так как право ЕАЭС в первую очередь ориентировано на достиже- 
ние общих целей социально-экономического развития, стоящих перед государствами-членами, которые отражены в ст. 4 Договора о ЕАЭС [14]. Составной частью экономической политики ЕАЭС является скоординированная научно-техническая и инновационная политика, призванная реализовать имеющийся научнотехнический потенциал каждого государства-члена и более того - сформировать и усилить интеграционный научно-технический потенциал. Единое экономическое пространство, по замыслу дополняемое единым научно-технологическим и инновационным пространством, является одним из форматов разработки и внедрения технологий, которые призваны вывести экономику стран ЕАЭС на новый технологический уровень.

Научно-технологическое сотрудничество, предусмотренное в ряде правовых актов ЕАЭС в качестве одного из направлений взаимодействия в рамках сотрудничества в промышленности, сельском хозяйстве (агропромышленном комплексе), а также транспортной области, исходит из необходимости технологической модернизации экономики, как на это указано в п. 3 «Инновационное развитие и модернизация экономики» раздела V «Основных направлений экономического развития Союза до 2030 г.» [15]. Реализация совместных инициатив в форме проектов и программ должна обеспечить дальнейшее углубление интеграционных процессов в сфере НИОКР и внедрение новых технологий.

Для государств ЕАЭС задача совершения технологического рывка, а именно ускорения технологической модернизации экономики и повышения инновационной активности вполне может рассматриваться как соответствующая той или иной задаче в рамках ЦУР. Так, одна из целей ЕАЭС состоит, например, в выравнивании уровня экономического и научнотехнологического развития и сокращения имеющихся здесь разрывов. Это не только будет способствовать сближению уровней дохода на душу населения в странах - членах объединения, но и будет содействовать достижению, в частности, ЦУР № 1, предполагающей ликвидацию нищеты.

Одновременно отметим, что в документах ЕАЭС можно видеть активное использование термина «устойчивое развитие» в смысле «устойчивого экономического развития», «макроэкономической устойчивости». Это связано с тем, что устойчивый экономический рост, обеспечиваемый ускоренной модернизацией по инновационному сценарию, - базовый приоритет ЕАЭС [16. С. 13]. Тем не менее это говорит об узкоспециальном понимании устойчивого развития, тогда как «в мире устойчивое развитие всегда рассматривается гораздо шире, с позиций сбалансированного развития трех компонент: социальной, экономической и экологической (иногда добавляется институциональная)» [17. С. 32]. На этом основании вполне справедливо высказывается критика в отношении того, что нормы Договора о ЕАЭС не в полной мере, т.е. только на уровне некоторых отдельных правил, отразили вопросы экологии и экологической безопасности [18], хотя, конечно, в ряде протоколов к Договору эти вопросы освещены более детально. Тем не менее по-прежнему сохраняется узость в использования экологического контроля и оценки [19. С. 67].

Высказанные критические соображения основаны на том, что фундаментальным показателем (индикатором) региональной политики устойчивого развития как такового является внимание к защите окружающей среды, что демонстрирует стремление сбалансировать измерения развития. Именно это внимание, кристаллизирующееся в форме последовательно проводимой политики, является «драйвером» разработки и дальнейшего использования особого рода научнотехнических средств и технологий, обеспечивающих устойчивый экономический рост не в узком, а в широком значении, т.е. как рост, сбалансированный с охраной окружающей среды в интересах нынешнего и будущих поколений.

В связи с тем, что устойчивое развитие не ограничивается устойчивым экономическим ростом, являющимся одним из компонентов развития в его современном понимании, как раз предопределило дальнейшую эволюцию и уточнение общей повестки функционирования Союза путем включения вопросов экологического, а равным образом социального характера. Думается, что это говорит о новом качественном уровне интеграционных процессов, т.е. их расширении и переходе к реализации проекта «зеленого» ЕАЭС. Это в свою очередь прямым образом отражается на конкретизации направлений скоординированной научно-технической политики в пользу разработки и внедрения не столько новых, сколько экологически чистых новых технологий и инноваций. Динамичное формирование глобальных рынков и потоков высокотехнологичной продукции, а особенно «зеленых технологий», - это вызов для ЕАЭС, на который предстоит ответить посредством интеграции в разработку и передачу данных потоков. Справочно укажем, что в последние годы, как отмечают эксперты, сектор «зеленых» НИОКР вышел на траекторию устойчивого роста [20].

Иными словами, целевой ориентир промышленного и иных видов экономического сотрудничества в условиях, когда ЕАЭС вышел на целенаправленное включение вопросов устойчивого развития в программу своей деятельности, не может не мыслиться в контурах перехода к устойчивому развитию, которое параллельно процессу смены технологических укладов. Это распространяется и на логику научнотехнического сотрудничества между государствами ЕАЭС, изначально предполагающего стремление решить проблемы повышения экономической конкурентоспособности в мире путем сложения потенциала. Отсюда следует, что смена технологических укладов в формате интеграции на уровне формирующейся региональной инновационной системы осуществляется в направлении формирования «зеленой экономики» в контексте стратегии устойчивого развития.

Поэтому столь значимыми оказываются положения, содержащиеся в разных источниках права ЕАЭС. В Договоре о ЕАЭС, как и в программностратегических и нормативно-правовых документах органов Союза, например в «Основных направлениях экономического развития Союза до 2030 г.», нацелен- 
ных на обеспечение мягкой координации экономической политики по сравнению с Договором, построенным по функциональному типу, а также иных документах предусматривается развитие регионального научно-технологического сотрудничества по весьма широкому спектру технологий, которые зачастую превосходят по своему объему перечень технологий, указанных в Повестке-2030.

Приложение к Рекомендации Коллегии ЕЭК от 28 февраля 2017 г. № 5 «Перечень приоритетных направлений сотрудничества государств - членов ЕАЭС в целях ускорения технологической модернизации и повышения инновационной активности организаций государств-членов с учетом прикладных и фундаментальных исследований, проводимых государствами-членами» [20] предусматривает разработку и использование технологий, которые являются, как нам представляется, важными для решения задач, относящихся к разным ЦУР. Данный перечень включает разработку новых лекарственных препаратов, развитие ресурсо- и энергосберегающих технологий, биотехнологий, технологий охраны окружающей среды, клеточных технологий.

Несмотря на приведенную выше критику понимания устойчивого развития, содержание которого до 2017 г. трактовалось на уровне ЕАЭС достаточно узко, оно в ряде случаев вполне соответствует содержательному формату ЦУР, в частности ЦУР № 8 «Содействие поступательному, всеохватному и устойчивому экономическому росту, полной и производительной занятости и достойной работе для всех». Задачи в рамках Цели включают в себя поддержание экономического роста на душу населения в соответствии с национальными условиями, обеспечение полной и производительной занятости и достойной работы для всех женщин и мужчин, в том числе молодых людей и инвалидов, равной оплаты за труд равной ценности.

Это говорит о том, что экономическая интеграция в рамках ЕАЭС, содействующая наращиванию интеграционного научно-технического потенциала, является не только основой экономической конкурентоспособности и достойного ответа на внешние вызовы, но и дополнительным фактором достижения целевых задач устойчивого развития. Данная проблематика дает о себе знать в ряде направлений сотрудничества, регулируемых правом ЕАЭС, особенно - в регулировании регионального и международного научнотехнического сотрудничества данного интеграционного объединения, предусмотренного как в Договоре о ЕАЭС (ст. 89.2, п. 6 ст. 92.4, п. 6 ст. 95.1), так и в других источниках права ЕАЭС - Протоколах, международных соглашениях в рамках ЕАЭС, решениях и распоряжениях органов Союза, в которых одновременно предусматриваются не только экономические, но и экологические и социальные аспекты интеграции. Это вполне заметно на примере так называемых «отраслей будущего» [22].

Несмотря на приоритетное значение экономических вопросов для интеграционных процессов в рамках ЕАЭС, экологические и социальные аспекты развития секторов экономики вполне могут быть отнесены к кругу вопросов, непосредственно находящихся в поле внимания государств - членов ЕАЭС и их органов. Данное обстоятельство не может не сказаться на укреплении экологического вектора научнотехнического сотрудничества и развития. К тому же, например, в Договоре о ЕАЭС в п. 7 ст. 86.2 сообщается о необходимости снижения воздействия транспорта на окружающую среду, что наполняет вполне определенным смыслом содержание п. 7 ст. 86.3, где говорится о развитии науки и инноваций в сфере транспорта.

В данном случае необходимо указать на евразийскую технологическую платформу (далее - ЕТП) «Технологии экологического развития». В качестве цели данной платформы выступает формирование механизмов повышения эффективности и конкурентоспособности экономик государств - членов ЕАЭС на основе внедрения экологически эффективных и энергосберегающих технологий. Сюда также отнесены такие цели, как решение экологических проблем и обеспечение экологической безопасности [23]. На круглом столе, прошедшем в декабре 2016 г. и посвященном вопросам взаимодействия и реализации кооперационных проектов в рамках ЕАЭС, участники ЕТП «Технологии экологического развития» представили первые результаты работы по профильным проектам, а также определили основные векторы дальнейшего развития проектов в ЕАЭС [24].

В последнее время международное сообщество большое внимание уделяет вопросам экологически обоснованного оборота опасных химических веществ. Подобного рода тематика включает акцент на разработку, передачу и использование соответствующих технологий и альтернатив. В данном русле идет право ЕАЭС, ряд соглашений которого нацелен на защиту окружающей среды в процессе оборота опасных химических веществ. Укажем на «Соглашение о перемещении озоноразрушающих веществ и содержащей их продукции и учете озоноразрушающих веществ при осуществлении взаимной торговли государств членов ЕАЭС» от 29 мая 2015 г. [25]. Оно регулирует порядок перемещения озоноразрушающих веществ и содержащей их продукции и одновременно подтверждает приверженность государств-членов принципам выполнения международных обязательств, предусмотренных Венской конвенцией об охране озонового слоя от 22 марта 1985 г. и Монреальского протокола по веществам, разрушающим озоновый слой от 16 сентября 1987 г.

Важное значение будет иметь в случае его принятия Соглашение о трансграничном перемещении опасных отходов по таможенной территории ЕАЭС [26]. В продолжение проблематики безопасного оборота опасных химических веществ, а также отказа от их ряда принят Технический регламент ЕАЭС «Об ограничении применения опасных веществ в изделиях электротехники и радиоэлектроники» (ТР ЕАЭС 037/2016). До момента его принятия в ЕАЭС не существовало нормативных актов, со всей определенностью ограничивающих применение опасных веществ в бытовых приборах.

В силу остроты вопроса о технологической модернизации производственной базы экономики госу- 
дарств-членов повышенной актуальностью характеризуется достижение ЦУР № 9 «Создание стойкой инфраструктуры, содействие всеохватной и устойчивой индустриализации и инновациям», предусматривающей широкое применение чистых и экологически безопасных технологий и промышленных процессов; активизацию научных исследований, стимулирование инновационной деятельности и значительное увеличение числа работников в сфере научно-исследовательских и опытно-конструкторских работ. Данная цель непосредственно коррелирует такой цели ЕАЭС, как модернизация экономики и увеличение валовой добавленной стоимости обрабатывающей промышленности на душу населения. Одновременно с этим в «Основных направлениях промышленного сотрудничества в рамках ЕАЭС» [27] некоторые предусматриваемые треки МИНТС государств-членов отражают экологический императив, например, необходимость генерирования и использования энерго- и ресурсосберегающих технологий (п. 7 «Ресурсосбережение и повышение энергоэффективности» Раздела V).

Согласно другому документу - Положению о разработке, финансировании и реализации межгосударственных программ и проектов в промышленной сфеpe [28], разработанному в целях реализации подп. 4.4.3 «Основных направлений промышленного сотрудничества в рамках ЕАЭС» (утв. Решением Евразийского межправительственного совета от 8 сентября 2015 г. № 9), в центре промышленного сотрудничества находится научно-техническое и инновационное сотрудничество. Предусматривается, что программа (проект) должны в обязательном порядке включать в себя оценку социально-экономических, экологических и иных последствий реализации программы (проекта) (п. 16 (3)).

Сегодня в ЕАЭС также ставится акцент на использовании, освоении новых технологий и их быстрого распространения в легкой промышленности в форме совместных проектов на базе объектов инновационной инфраструктуры инжиниринговых центров, технопарков, бизнес-инкубаторов и т.д. В приложении № 1 «Перечень перспективных направлений исследований и разработок в сфере легкой промышленности, а также научных организаций и предприятий, их осуществляющих» к рекомендации ЕЭК № 28 от 13 декабря 2016 г. [29] содержится указание на разработку и внедрение эффективных и экологически чистых технологий отделки тканевых материалов, ресурсосберегающие и энергосберегающие технологии окраски и отделки тканей.

В дополнение к сказанному в планах ЕЭК - расширение тематики интеграционных процессов в сфере энергетики по таким направлениям, как энергоэффективность и энергосбережение, использование возобновляемых источников энергии и улучшение экологической ситуации. Таким образом, расширяется поле разработки и применения инновационных подходов в энергетике, что выступает фактором устойчивого развития энергетики ЕАЭС. По этой причине в 2017 г. ЕЭК на уровне департамента энергетики осуществляла работу по дополнению положений Договора о Союзе от 29 мая 2014 г. ст. 79.1 «Скоордини- рованная энергетическая политика в рамках Союза» в целях закрепления принципов скоординированной энергетической политики в части сотрудничества по вопросам энергосбережения, энергоэффективности, улучшения экологической ситуации и использовании атомной энергии в мирных целях. Все это в практическом плане предполагает использование нового оборудования и новых технологий, что вызвано отставанием государств ЕАЭС от развитых государств в области энергоемкости экономики в среднем в 2 раза. В сущности, в ближайшей перспективе будет сформировано новое направление энергетического сотрудничества, представленное соответствующей научно-технологической и инновационной интеграцией.

Другим важным сектором, требующим технологической модернизации, выступает агропромышленный комплекс. В приложении к Рекомендации № 14 «О перечне перспективных научно-исследовательских и опытно-конструктивных работ в сфере агропромышленного комплекса государств - членов ЕАЭС до 2020 г.» [30] предусматривается разработка ресурсо- и энергосберегающих технологий и технических средств для глубокой переработки зерновых и овощных культур, биологических средств защиты овощных культур от болезней и вредителей, ресурсо- и энергосберегающих технологий. Данные НИОКР направлены на создание высокоурожайных культур, что в целом вносит вклад в достижение ЦУР № 2. Далее данный перечень нашел свою конкретизацию в плане НИОКР на период до 2020 г. [31], рассчитанного не только на повышение эффективности взаимодействия на основе объединения научного потенциала государств-членов в форме совместных проектов, но и на исключение дублирование НИОКР в агропромышленной сфере.

Активизация скоординированной политики ЕАЭС в сфере достижения ЦУР оказалась синхронизирована со значительными успехами в сфере институционализации регионального научно-технического сотрудничества, в частности в сфере трансфера технологий. Это вызвано тем, что основная проблема для ЕАЭС не столько стимулирование технологических разработок, сколько, как отмечает А.В. Гаврилюк, создание широкого слоя высокотехнологичного предпринимательства [32. С. 115]. Но здесь существует и еще одна проблема, заключающаяся в разрозненности сектора НИОКР и предприятий, вследствие чего последние не могут адресовать свои технологические запросы и получить предложения о сотрудничестве со стороны разработчиков. С проблемой адресации сталкиваются также и разработчики технологий. В случае активизации и эффективного функционирования система передачи технологий, особенно инновационных, имеющая многоуровневый характер, внесет существенный вклад в модернизацию экономики и общества.

Безусловно, основой для интенсификации разработки и передачи «чистых» технологий внутри ЕАЭС призвана стать Евразийская сеть трансфера технологий, представляющая собой, в сущности, единую информационную сеть, предполагающая повышение потенциала коммуникационных навыков 
всех заинтересованных организаций в целях укрепления всех звеньев инновационного цикла. Важным достижением, с учетом акцентирования в Повестке2030 вопросов передачи технологии, стало утверждение Концепции создания и функционирования Евразийской сети трансфера технологий [33], разработанной в целях реализации п. 4.4.5 «Основных направлений промышленного сотрудничества в рамках ЕАЭС», утвержденных Решением Евразийского межправительственного совета от 8 сентября 2015 г. № 9. Концепция, основанная на лучшем мировом опыте создания и развития подобных сетей, включила в себя согласованные принципы функционирования Сети, а также форматы и механизмы внутрисистемного взаимодействия, а также развития национальных сегментов данной сети.

Ее создание позволит посредством объединения разрозненных национальных сетей в общую систему сформировать в ЕАЭС имеющую инновационный характер информационную и коммуникационную инфраструктуру, являющуюся организационной платформой для обеспечения передовых форм сотрудничества государств ЕАЭС, что приведет к повышению уровня инновационной активности предприятий и, в конечном счете, - к обеспечению конкурентоспособности промышленной продукции. Основанием таких ожиданий является множественность ее субъектов, к которым относятся заинтересованные предприятия, научные организации, технопарки, инновационно-технологические центры, центры трансфера технологий и т.д.

С точки зрения автора статьи, существенным компонентом научно-технологической интеграции ЕАЭС в целях устойчивого развития является активное внешнее международное научно-технологическое сотрудничество с различными субъектами - правительствами третьих стран, международными организациями, интеграционными объединениями государств. Можно видеть, что в настоящее время ЕЭК развернула активную деятельность на международном треке функционирования Союза. Заключены меморандумы и декларации о сотрудничестве с отдельными государствами, их интеграционными объединениями и международными организациями (ФАО, ЮНИДО и др.), в которых предусматриваются вопросы разработки технологических инноваций и обмена ими. Однако, как следует из сказанного, основы такого взаимодействия в настоящее время имеют пока политическую, а не правовую природу. По нашему мнению, данный аспект интеграционного проекта ЕАЭС заслуживает самостоятельного системного исследования, в том числе сквозь призму обоснования необходимости развития договорной базы в сфере внешнего МНТС.
В заключение следует сформулировать ряд выводов из проведенного исследования.

Во-первых, серьезное отношение ЕАЭС к достижению ЦУР на региональном уровне расширяет содержательный масштаб региональной научнотехнологической и инновационной интеграции. Это позволяет утверждать о необходимости дальнейшего развития содержания регионального научнотехнического и инновационного сотрудничества как в плане формирования соответствующей инфраструктуры, так и в плане обеспечения его эффективного правового регулирования в контексте обеспечения прямой и обратной связи между углублением интеграции и устремленностью к достижению ЦУР.

Во-вторых, следует учитывать, что в Повестке-2030 говорится о синергии всех средств достижения ЦУР финансов, технологий, инвестиций и торговли (ЦУР № 17). Это весьма значимо для ЕАЭС. Так, важнейшим условием развития сектора высоких технологий и инноваций в промышленности, сельском хозяйстве и энергетике как условиях структурной и технологической модернизации экономики являются инвестиционные и финансовые потоки, которые должны быть адекватны для достижения данной экономической цели интеграции. Поэтому темпы перехода ЕАЭС к устойчивому развитию зависят не только от активности научно-технической и инновационной политики, эффективности реализации инфраструктурных инициатив и инновационных проектов на уровне ЕАЭС в целом и его государств-членов в частности, но и от формирования и эффективного функционирования финансовых и инвестиционных механизмов, уровня и характера деловой активности и, соответственно, от эффективности их правового регулирования.

B-третьих, как нам представляется, успешная деятельность по диверсификации экономики, в том числе на основе технологической модернизации, одновременно с усилиями по улучшению структуры торговли и инвестиций государств-членов, устранением барьеров, изъятий и ограничений на внутреннем рынке, будет способствовать углублению и расширению не только внутреннего, т.е. регионального, но и внешнего МИНТС ЕАЭС.

В-четвертых, залогом необратимого превращения региональной научно-технологической интеграции на уровне ЕАЭС в фактор, обеспечивающий переход Союза по путь к устойчивому развитию и достижению его целей, является более интенсивное включение в интеграционный проект экологической проблематики и, соответственно, развитие экологического законодательства ЕАЭС.

\section{ЛИТЕРАТУРА}

1. Преобразование нашего мира: Повестка дня в области устойчивого развития на период до 2030 года // A/RES/70/1 (25 сентября 2015 года). URL: http://www.un/org/ru/documents/ods.asp?m=A/RES/70/1 (дата обращения: 11.06.2018).

2. European Commission. The EU made a positive and constructive contribution to the development of the 2030 Agenda for Sustainable Development. URL: https://ec.europa.eu/europeaid/policies/european-development-policy (дата обращения: 11.06.2018).

3. Андронова И.В. Научно-техническое сотрудничество в рамках ЕАЭС как важнейший фактор лояльности населения стран-участниц к интеграционному объединению и его притягательности для новых членов // Вестник Российского университета дружбы народов. Сер.: Социология. 2018. № 1. С. 117-130.

4. Гаврилюк А.В. Перспективы интеграционного технологического развития государств - членов ЕАЭС // Государственное управление. Электронный вестник. 2015. Вып. № 51. С. 21. 
5. Научно-техническое сотрудничество как фактор евразийской экономической интеграции: Ежегодный доклад интеграционного клуба при Председателе Совета Федерации Федерального Собрания Российской Федерации за 2015 год. Приложение № 8. Научноинновационный потенциал стран ЕАЭС - необходимость единой стратегии : материал Ин-та междунар. исслед. МГИМО (У) МИД России. 122 c. URL: http://www.council.gov.ru/activity/analytics/analytical_reports/65859/ (дата обращения: 19.04.2018).

6. Mussatayev S., Kaidarova A., Mekebaeva M. Problems and prospects of the Eurasian Economic Union: SWOT analysis // Świat Idei i Polityki. 2016. Vol. 15, № 26. P. 194-208.

7. Dragneva R., Wolczuk K. The Eurasian Economic Union: deals, rules and the exercise of power. Research Paper, 2017.25 p. URL: http://www.chathamhouse.org/sites/default/files/publications/research/2017-05-02-eurasian-economic-union-dragneva-wolczuk.pdf (дата обpaщения: 7.06.2018).

8. Vinokurov E. Eurasian Economic Union: current state and preliminary results // Russian Journal of Economics. 2017. № 2. P. 54-70.

9. Lagutina M. Eurasian Economic Union Foundation: issues of global regionalization // Eurasian Border Review. 2014. Vol. 5, № 2. P. 95-112.

10. В Бишкеке обсудили вопросы сотрудничества в интересах устойчивого развития в трехстороннем формате: РФ - КР - ПРООН (17.03.2017). URL: http://www.ca-portal.ru/article:33780 (дата обращения: 15.06.2018).

11. Доклад Евразийской экономической комиссии «Показатели достижения Целей в области устойчивого развития в регионе ЕАЭС». 56 с. URL: http://www.eurasiancommission.org/act/integr-i-makroec/Documents/OON_Rus.pdf (дата обращения: 24.05.2018).

12. Урсул А.Д. Цели устойчивого развития: глобальные и евразийские перспективы. 9 c. URL: http://www.terraviva.ru/img/news2015/dokl_ursul.pdf (дата обращения: 24.05.2018).

13. Message from President of Russia to heads Eurasian Economic Union member states (18 January 2018). URL: http://en.kremlin.ru/events/president/news/56663 (дата обращения: 25.04.2018).

14. Договор о ЕАЭС (Астана, 29.05.2014 г.) (с изм. и доп. от 12.02.2017 г.). URL: https://docs.eaeunion.org/docs/ruus/0027353/itia_05062014_doc.pdf(дата обращения: 18.05.2018 г.).

15. Высший Евразийский экономический совет. Решение № 28 от 16.10.2015 г. «Основные направления экономического развития ЕАЭС до 2030 г.» (г. Бурубай). URL: https://docs.eaeunion.org/docs/ru-ru/0148763/scd_19102015_28 (дата обращения: 15.04.2018).

16. Сулейменов Т.М. Приоритеты интеграции // Евразийская интеграция: экономика, право, политика. 2015. № 12. С. 7-13.

17. Бобылев С.Н., Соловьева С.В. ООН: смена целей // Мировая экономика и международные отношения. 2016. Т. 60, № 5. С. 30-39.

18. Боклан Д.С. Охрана окружающей среды в контексте евразийской интеграции (международно-правовой аспект) // Евразийский юридический журнал. 2015. № 1. С. 25-28.

19. Кудусов И.И. ЕАЭС в условиях глобализации, экологизации и эволюции ИТ // Электронный междисциплинарный научный журнал «Интернаука». 2017. № 5. Р. 66-71.

20. Есина Е. Зеленые инновации для экологической рациональности // Партнер ЕАЭС. 2018. № 1. С. $94-97$.

21. Приложение к Рекомендации Комиссии ЕЭК от 28 февраля 2017 № 5 «Перечень приоритетных направлений сотрудничества государств - членов ЕАЭС в целях ускорения технологической модернизации и повышения инновационной активности организаций государств-членов с учетом прикладных и фундаментальных исследований, проводимых государствами-членами». URL: https://docs.eaeunion.org/docs/ru-ru/01417291/clcr_02032017 (дата обращения: 12.05.2018).

22. Распоряжение Евразийского Межправительственного совета № 2 «О сферах экономики, обладающих интеграционным потенциалом в Евразийском экономическом союзе, и мерах, направленных на его использование» (Бишкек, от 7 марта 2017 года 7 марта 2017 года). URL: https://docs.eaeunion.org/docs/ru-ru/01415075/ico_09032017 (дата обращения: 13.05.2018).

23. Паспорт евразийской технологической платформы «Технологии экологического развития» // Приложение к Распоряжению Совета ЕЭК от 18 октября 2016 № 32 «О формировании приоритетных евразийских технологических платформ». URL: https:/docs.eaeunion.org/docs/ ru-ru/01414433/cnco_06032017_32 (дата обращения: 1.06.2018).

24. Экологическое развитие ЕАЭС получило первые проекты (09.12.2016). URL: http://eec.eaeunion.org/ru/nae/news/Pages/12-12/2-16-3.aspx (дата обращения: 5.06.2018).

25. Соглашение о перемещении озоноразрушающих веществ и содержащей их продукции и учете озоноразрушающих веществ при осуществлении взаимной торговли государств - членов ЕАЭС (Бурубай, 29 мая 2015 г.). URL: https://docs.eaeunion.org/docs/ruru/0147901/itia_02062015 (дата обращения: 5.06.2018).

26. Совет ЕЭК. Распоряжение № 4 «О проекте Соглашения о трансграничном перемещении опасных отходов по таможенной территории ЕЭС» (Москва, 13 января 2017 г.). URL: https://docs.eaeunion.org/docs/ru-ru/01417586/cnco_03032017 (дата обращения: 5.06.2018).

27. Евразийский межправительственный совет. Решение № 9 «Об основных направлениях промышленного сотрудничества в рамках ЕАЭС» (Гродно, 9 сентября 2015 г.). URL: https://docs.eaeunion.org/docs/ru-ru/0148480/icd_10092015_9 (дата обращения: 14.05.2018).

28. Евразийский межправительственный совет. Решение № 1 «Об утверждении Положения о разработке, финансировании и реализации межгосударственных программ и проектов в промышленной сфере» (Алматы, 2 февраля 2018 г.). URL: https://docs.eaeunion.org/docs/ruru/01416877/icd_05022018_1// (дата обращения: 20.05.2018).

29. Коллегия ЕЭК. Рекомендация № 28 «О реализации совместных проектов по освоению и применению государствами - членами ЕАЭС новых технологий в легкой промышленности» (Москва, 13 декабря 2016 г.). URL: https://docs.eaeunion.org/docs/ru-ru/01414486/clcr _15122016_28 (дата обращения: 21.05.2018).

30. Коллегия ЕЭК. Рекомендация № 14 «О перечне перспективных научно-исследовательских и опытно-конструктивных работ в сфере агропромышленного комплекса государств - членов ЕЭС до 2020 г.» (Москва, 8 июля 2015 г.). URL: https://docs.eaeunion.org/docs/ruru/0148046/clco_09072015_14 (дата обращения: 17.04.2018).

31. Коллегия ЕЭК. Рекомендация № 25 « координации совместной научной и инновационной деятельности государств - членов ЕАЭС в сфере агропромышленного комплекса» (Москва, 13 декабря 2016 г.). URL: https://docs.eaeunion.org/docs/ru-ru/01414525/clco_ 15122016_25 (дата обращения: 18.05.2018).

32. Гаврилюк А.В. Трансфер технологий в условиях международной экономической интеграции стран ЕАЭС // Государственное управление: электронный вестник. 2015. № 52. Октябрь. С. 101-119.

33. Концепция создания и функционирования евразийской сети трансфера технологий: Утверждена Решением № 23 Совета Евразийской экономической комиссии от 30 марта 2018 г. URL: https://docs.eaeunion.org/docs/ru-ru/01417246/cncd_02042018_23 (дата обращения: 21.05.2018).

Статья представлена научной редакцией «Педагогика» 13 сентября 2018 г.

SCIENTIFIC AND TECHNOLOGICAL INTEGRATION OF THE EAEU AS A FACTOR OF ACHIEVING THE SUSTAINABLE DEVELOPMENT GOALS: ANALYZING THE LEGAL FOUNDATION

Vestnik Tomskogo gosudarstvennogo universiteta - Tomsk State University Journal, 2018, 436, 243-251.

DOI: $10.17223 / 15617793 / 436 / 30$

Mark V. Shugurov, Saratov State Law Academy (Saratov, Russian Federation). E-mail: shugurovs@mail.ru

Keywords: Eurasian Economic Union; technology transfer; sustainable development; environment protection; agroecology; green technology. 
This article examines the legal foundations of the Eurasian Economic Union in the area of science, technologies and innovation in the context of the regional policy of transition to sustainable development and achieving its goals (Sustainable Development Goals/SDGs) as a new aspect of the phenomenon of Eurasian integration. The subject matter of the present study is the impact of SDGs on the EAEU legal policy of technological modernizing the economy. The article aims to ascertain the conformity of the EAEU law with solving the task of transition to sustainable development in the aspect of encouraging the development and transfer of ecologically sound technologies. For this purpose, the author has analyzed the provisions of the EAEU hard and soft law in detail. The research methods used in the study were both general (analysis, synthesis, abstracting and generalization) and specific (historical legal and comparative legal). The theoretical foundations were notions that the means to harmonize the three dimensions of development (social, economic and ecological) are to use relative technologies. Their development and transfer are in the focus of strategical documents concerning sustainable development, including the Agenda for Sustainable Development till 2030. Based on these scientific methods and a theoretical approach, the author has explored key sectoral work streams of the EAEU legal policy in the area of the development and transfer of the mentioned technologies, first of all, technologies in industry and agroindustry. Simultaneously, the institutional background of the Eurasian Technology Platforms and the Eurasian Network of Technology Transfer has been described. As stressed by the author, an essential component of the EAEU scientific and technological integration for sustainable development is collaboration with governments of third states, international organizations and states' regional integrative alliances. That is why, much attention is paid to the scientific and technological collaboration with other states and international organizations (FAO, UNIDO). The framework basis of this collaboration is essentially political rather than legal. Hence, the development of the legal foundations of this collaboration has prospects. The author proves the provision that the EAEU law provides for modernizing economy and society of member-states for the development and transfer of ecologically sound technologies to different branches of economy with the aim of forming a "Green Union". A conclusion is made that the technological modernization of the EAEU in ecocentric terms on the basis of ESTs demands: (1) synergy between all means of transition to sustainable development, in particular, technologies, investments, trade developing and financial resources accumulating; (2) deeper economic integration at the regional level and increase of economic and scientific and technological cooperation with third countries, their regional alliances and international organizations; (3) a coordinated ecological policy of member states, a developed regional ecological legislation, an elaborated regional strategy of sustainable development.

\section{REFERENCES}

1. UN. (2015) Transforming our world: the 2030 Agenda for Sustainable Development. [Online] Available from: http://www.un.org/en/development/desa/population/migration/generalassembly/docs/globalcompact/A_RES_70_1_E.pdf. (Accessed: 11.06.2018).

2. European Commission. (n.d.) The EU made a positive and constructive contribution to the development of the 2030 Agenda for Sustainable Development. [Online] Available from: https://ec.europa.eu/europeaid/policies/european-development-policy. (Accessed: 11.06.2018).

3. Andronova, I.V. (2018) Scientific-technical cooperation within the EAEU as a key factor of the loyalty of the participating countries' population to the integration and of its attractiveness for new members. Vestnik Rossiyskogo universiteta druzhby narodov. Seriya: Sotsiologiya - RUDN Journal of Sociology. 1. pp. 117-130. (In Russian). DOI: 10.22363/2313-2272-2018-18-1-117-130

4. Gavrilyuk, A.V. (2015) Perspektivy integratsionnogo tekhnologicheskogo razvitiya gosudarstv - chlenov EAES [Prospects for the integration of technological development of the EAEU Member States]. Gosudarstvennoe upravlenie. Elektronnyy vestnik. 51.

5. Russian Federation. (2015) Nauchno-tekhnicheskoe sotrudnichestvo kak faktor evraziyskoy ekonomicheskoy integratsii: Ezhegodnyy doklad integratsionnogo kluba pri Predsedatele Soveta Federatsii Federal'nogo Sobraniya Rossiyskoy Federatsii za 2015 god. Prilozhenie № 8. Nauchnoinnovatsionnyy potentsial stran EAES - neobkhodimost' edinoy strategii [Scientific and technical cooperation as a factor of Eurasian economic integration: Annual report of the integration club under the Chairman of the Council of Federation of the Federal Assembly of the Russian Federation for 2015. Appendix No. 8. The scientific and innovative potential of the EAEU countries: the need for a unified strategy]. [Online] Available from: http://www.council.gov.ru/activity/analytics/analytical reports/65859/. (Accessed: 19.04.2018).

6. Mussatayev, S., Kaidarova, A. \& Mekebaeva, M. (2016) Problems and prospects of the Eurasian Economic Union: SWOT analysis. Świat Idei $i$ Polityki. 15(26). pp. 194-208.

7. Dragneva, R. \& Wolczuk, K. (2017) The Eurasian Economic Union: deals, rules and the exercise of power. Research Paper. [Online] Available from: http://www.chathamhouse.org/sites/default/files/publications/research/2017-05-02-eurasian-economic-union-dragneva-wolczuk.pdf. (Accessed: 7.06.2018).

8. Vinokurov, E. (2017) Eurasian Economic Union: current state and preliminary results. Russian Journal of Economics. 2. pp. 54-70. DOI: 10.1016/j.ruje.2017.02.004

9. Lagutina, M. (2014) Eurasian Economic Union Foundation: issues of global regionalization. Eurasian Border Review. 5(2). pp. 95-112.

10. Ca-portal.ru. (2017) V Bishkeke obsudili voprosy sotrudnichestva $v$ interesakh ustoychivogo razvitiya $v$ trekhstoronnem formate: RF - KR $P R O O N$ [In Bishkek, issues of cooperation for sustainable development in a tripartite format were discussed: the Russian Federation - the Kyrgyz Republic - UNDP]. [Online] Available from: http://www.ca-portal.ru/article:33780. (Accessed: 15.06.2018).

11. Eurasian Economic Commission. (2017) Pokazateli dostizheniya Tseley v oblasti ustoychivogo razvitiya $v$ regione EAES [Indicators of achieving the Sustainable Development Goals in the EAEU region]. [Online] Available from: http://www.eurasiancommission.org/ru/act/ integr_i_makroec/Documents/OON_Rus.pdf. (Accessed: 24.05.2018).

12. Ursul, A.D. (2015) Tseli ustoychivogo razvitiya: global'nye i evraziyskie perspektivy [Goals of sustainable development: global and Eurasian perspectives]. [Online] Available from: http://www.terra-viva.ru/img/news2015/dokl_ursul.pdf. (Accessed: 24.05.2018).

13. Kremlin.ru. (2018) Message from President of Russia to heads Eurasian Economic Union member states (18 January 2018). [Online] Available from: http://en.kremlin.ru/events/president/news/56663. (Accessed: 25.04.2018).

14. EAEU. (2017) Dogovor o EAES (Astana, 29.05.2014 g.) (s izm. i dop. ot 12.02.2017 g.) [Treaty on the EAEU (Astana, May 29, 2014) (as amended and supplemented on February 12, 2017)]. [Online] Available from: https://docs.eaeunion.org/docs/ru-us/0027353/itia_05062014_doc.pdf. (Accessed: 18.05.2018).

15. EAEU. (2015) Vysshiy Evraziyskiy ekonomicheskiy sovet. Reshenie № 28 ot 16.10.2015 g. "Osnovnye napravleniya ekonomicheskogo razvitiya EAES do 2030 g." (g. Burubay) [Higher Eurasian Economic Council. Decision No. 28 of October 16, 2015, "The main directions of economic development of the EAEU until 2030" (Burubay)]. [Online] Available from: https://docs.eaeunion.org/docs/ru-ru/0148763/scd_19102015_28. (Accessed: 15.04.2018).

16. Suleymenov, T.M. (2015) Prioritety integratsii [Integration priorities]. Evraziyskaya integratsiya: ekonomika, pravo, politika. 12 . pp. 7-13.

17. Bobylev, S.N. \& Solov'eva, S.V. (2016) United Nations: redefining goals. Mirovaya ekonomika i mezhdunarodnye otnosheniya - World Economy and International Relations. 60(5). pp. 30-39.

18. Boklan, D.S. (2015) Environmental protection in the context of Eurasian economic integration (international legal aspect). Evraziyskiy yuridicheskiy zhurnal - Eurasian Law Journal. 1. pp. 25-28. (In Russian). 
19. Kudusov, I.I. (2017) EAES v usloviyakh globalizatsii, ekologizatsii i evolyutsii IT [EAEU in the context of globalization, greening and IT evolution]. Internauka. 5. pp. 66-71.

20. Esina, E. (2018) Zelenye innovatsii dlya ekologicheskoy ratsional'nosti [Green Innovations for Ecological Sustainability]. Partner EAES. 1. pp. 94-97.

21. EAEU. (2017) Prilozhenie k Rekomendatsii Komissii EEK ot 28 fevralya 2017 № 5 "Perechen' prioritetnykh napravleniy sotrudnichestva gosudarstv - chlenov EAES v tselyakh uskoreniya tekhnologicheskoy modernizatsii i povysheniya innovatsionnoy aktivnosti organizatsiy gosudarstvchlenov s uchetom prikladnykh i fundamental'nykh issledovaniy, provodimykh gosudarstvami-chlenami" [Annex to the Recommendation of the ECE Commission of February 28, 2017 No. 5 "A list of priority areas for cooperation between the EAEU member states in order to accelerate technological modernization and increase the innovation activity of organizations of member states, taking into account applied and basic research conducted by member states"]. [Online] Available from: https://docs.eaeunion.org/docs/ru-ru/01417291/clcr_02032017. (Accessed: 12.05.2018).

22. EAEU. (2017) Rasporyazhenie Evraziyskogo Mezhpravitel'stvennogo soveta № 2 "O sferakh ekonomiki, obladayushchikh integratsionnym potentsialom v Evraziyskom ekonomicheskom soyuze, i merakh, napravlennykh na ego ispol'zovanie" (Bishkek, ot 7 marta 2017 goda) [Order of the Eurasian Intergovernmental Council No. 2 "On economic sectors with integration potential in the Eurasian Economic Union, and measures aimed at its use" (Bishkek, March 7, 2017)]. [Online] Available from: https://docs.eaeunion.org/docs/ru-ru/01415075/ico_09032017. (Accessed: 13.05.2018).

23. EAEU. (2016) Pasport evraziyskoy tekhnologicheskoy platformy "Tekhnologii ekologicheskogo razvitiya" [Passport of the Eurasian technological platform "Technologies of environmental development"]. [Online] Available from: https://ocs.eaeunion.org/docs/ru-ru/01414433/ cnco 06032017 32. (Accessed: 1.06.2018).

24. EAEU. (2016) Ekologicheskoe razvitie EAES poluchilo pervye proekty [The environmental development of the EAEU received the first projects]. [Online] Available from: http://eec.eaeunion.org/ru/nae/news/Pages/12-12/2-16-3.aspx. (Accessed: 5.06.2018).

25. EAEU. (2015) Soglashenie o peremeshchenii ozonorazrushayushchikh veshchestv i soderzhashchey ikh produktsii i uchete ozonorazrushayushchikh veshchestv pri osushchestvlenii vzaimnoy torgovli gosudarstv - chlenov EAES (Burubay, 29 maya 2015 g.) [Agreement on the movement of ozone-depleting substances and products containing them and accounting for ozone-depleting substances in the implementation of mutual trade of the EAEU Member States (Burubay, May 29, 2015)]. [Online] Available from: https://docs.eaeunion.org/docs/ru$\mathrm{ru} / 0147901 /$ itia 02062015. (Accessed: 5.06.2018).

26. EAEU. (2017) Sovet EEK. Rasporyazhenie № 4 “O proekte Soglasheniya o transgranichnom peremeshchenii opasnykh otkhodov po tamozhennoy territorii EES" (Moskva, 13 yanvarya 2017 g.) [Council of EEC. Instruction No. 4 "On the draft Agreement on the Transboundary Movement of Hazardous Wastes on the Customs Territory of the EAEU" (Moscow, January 13, 2017)]. [Online] Available from: https://docs.eaeunion.org/docs/ru-ru/01417586/cnco_03032017. (Accessed: 5.06.2018).

27. EAEU. (2015) Evraziyskiy mezhpravitel'stvennyy sovet. Reshenie № 9 "Ob osnovnykh napravleniyakh promyshlennogo sotrudnichestva $v$ ramkakh EAES" (Grodno, 9 sentyabrya 2015 g.). [Eurasian Intergovernmental Council. Decision No. 9 "On the main areas of industrial cooperation within the EAEU" (Grodno, September 9, 2015)]. [Online] Available from: https://docs.eaeunion.org/docs/ru-ru/0148480/icd_10092015_9. (Accessed: 14.05.2018).

28. EAEU. (2018) Evraziyskiy mezhpravitel'stvennyy sovet. Reshenie № 1 “Ob utverzhdenii Polozheniya o razrabotke, finansirovanii i realizatsii mezhgosudarstvennykh programm i proektov v promyshlennoy sfere” (Almaty, 2 fevralya 2018 g.) [Eurasian Intergovernmental Council. Decision No. 1 "On the approval of the Regulations on the Development, Financing and Implementation of Interstate Programs and Projects in the Industrial Sphere" (Almaty, February 2, 2018)]. [Online] Available from: https://docs.eaeunion.org/docs/ru-ru/01416877/icd_05022018_1//. (Accessed: 20.05.2018).

29. EAEU. (2016) Kollegiya EEK. Rekomendatsiya № 28 "O realizatsii sovmestnykh proektov po osvoeniyu i primeneniyu gosudarstvami - chlenami EAES novykh tekhnologiy v legkoy promyshlennosti" (Moskva, 13 dekabrya 2016 g.) [Collegium of EEC. Recommendation No. 28 on the implementation of joint projects for the development and application of new technologies in the light industry by the EAEU member states (Moscow, December 13, 2016)]. [Online] Available from: https://docs.eaeunion.org/docs/ru-ru/01414486/clcr_15122016_28. (Accessed: 21.05.2018).

30. EAEU. (2015) Kollegiya EEK. Rekomendatsiya № 14 "O perechne perspektivnykh nauchno-issledovatel'skikh i opytno-konstruktivnykh rabot v sfere agropromyshlennogo kompleksa gosudarstv - chlenov EES do $2020 \mathrm{~g}$." (Moskva, 8 iyulya $2015 \mathrm{~g}$.) [Recommendation No. 14 "On the list of promising research and developmental and constructive works in the field of the agro-industrial complex of the EEC Member States until 2020" (Moscow, July 8, 2015)]. [Online] Available from: https://docs.eaeunion.org/docs/ru-ru/0148046/clco_09072015_14. (Accessed: 17.04.2018).

31. EAEU. (2016) Kollegiya EEK. Rekomendatsiya № 25 "O koordinatsii sovmestnoy nauchnoy i innovatsionnoy deyatel’nosti gosudarstv - chlenov EAES v sfere agropromyshlennogo kompleksa" (Moskva, 13 dekabrya 2016 g.) [Collegium of EEC. Recommendation No. 25 "On the coordination of joint research and innovation activities of the EAEU Member States in the field of the agro-industrial complex" (Moscow, December 13, 2016)]. [Online] Available from: https://docs.eaeunion.org/docs/ru-ru/01414525/clco_15122016_25. (Accessed: 18.05.2018).

32. Gavrilyuk, A.V. (2015) Technology transfer in the conditions of international economic integration of the EAEU Gosudarstvennoe upravlenie: elektronnyy vestnik - Public Administration. E-Journal. 52. October. pp. 101-119. (In Russian).

33. EAEU. (2018) Kontseptsiya sozdaniya i funktsionirovaniya evraziyskoy seti transfera tekhnologiy: Utverzhdena Resheniem № 23 Soveta Evraziyskoy ekonomicheskoy komissii ot 30 marta $2018 \mathrm{~g}$. [The concept of creating and operating a Eurasian technology transfer network: Approved by Decision No. 23 of the Council of the Eurasian Economic Commission of March 30, 2018]. [Online] Available from: https://docs.eaeunion.org/docs/ru-ru/01417246/cncd_02042018_23. (Accessed: 21.05.2018).

Received: 13 September 2018 